\title{
Finansal Derinliğin Kırılgan Beşli Ekonomileri Üzerindeki Etkisi
}

\author{
DOI: 10.26466/opus.930561 \\ * \\ Ferhat Șirin Sökmen * \\ * Dr. Öğr. Üyesi., Şırnak Üniversitesi, Şırnak/Türkiye \\ E-Posta: : sokmenferhat@sirnak.edu.tr \\ ORCID: $\underline{0000-0002-9563-3526}$
}

\section{Öz}

Finansal sistemdeki gelişme ekonomik büyüme performansının artırılması için önemlidir. Zira finansal sistemdeki pozitif değişim büyümeyi sağlayan yatırım ve tüketim kararlarının verilmesini de olumlu bir şekilde etkileyecektir. Bununla birlikte finansal gelişmişliğin ölçümünde kullanılan göstergelerden bir tanesi olan finansal derinlik, gelişmekte olan ülkelerin finansal sistemden ne derece yararlanabildiğini gösteren önemli bir endekstir. Finansal derinliği sağlamak amacı ile gerek yurtiçi tasarrufların gerekse küresel sermaye akımlarının finansal sisteme girişi önem arz etmektedir. Bu çalışmada finansal derinliğin ekonomik büyüme üzerindeki etkisi "kırılgan beşli" olarak tabir edilen ve finansal sistemlerinin dış finansmana bağımlılılar ile bilinen Türkiye, Güney Afrika, Brezilya, Hindistan ve Endonezya ekonomilerinde 1980 ve 2018 yılları arasında kalan dönemlere ait veriler ışı̆̆ında panel veri analiz yöntemleri ile test edilmektedir. Test sonuçları göstermektedir ki, ülke grubunda kısa ve uzun dönemde çift yönlü nedenselliğin varlığından bahsetmek mümkün iken, ülke bazl analizler sonucunda finansal derinlikten ekonomik büyümeye doğru Brezilya, Hindistan ve Güney Afrika ekonomilerinde tek yönlü bir nedenselliğin bulunduğu söylenebilir.

Anahtar Kelimeler: Kırılgan beşli, Finansal derinlik, Panel veri analizi 


\title{
The Effect of Financial Depth on Fragile Five Economies
}

\begin{abstract}
Improvement in the financial system is important to increase economic growth performance. Because the positive change in the financial system positively affects the investment and consumption decisions ensuring growth. In the meantime, the financial depth that is one of the indicators of financial development measurement is a remarkable index revealing the degree of benefiting from the financial system in terms of developing countries. The entry of both domestic savings and global capital flows into the financial system is crucial to provide the financial depth. This study utilized panel data analysis methods to test the effect of financial depth on economic growth in the light of data of Turkish, South African, Brazilian, Indian, and Indonesian economies that are called fragile five and also well-known with their financial systems' dependency to external financing for the period between 1980 and 2018. Test results show that it is possible to talk about two-way causality for the country group in the short and long term while there is only a one-way causality from financial depth to Brazilian, Indian, and South African economies.
\end{abstract}

Keywords: Fragile five, Financial depth, Panel data analysis 


\section{Giriş}

Finansal gelişmişlik seviyesinin ekonomik büyümeye yapmış olduğu katkı son yıllarda sıkça incelenen konulardan bir tanesi haline gelmiştir. Özellikle gelişmekte olan ülkelerde üretim faktörlerinden sermayede yaşanan kıtlık finansal sistem aracılı̆̆ı ile giderilmektedir. Obstfeld'e (1994) göre iyi çalışan finansal piyasalar yüksek ekonomik büyüme oranına ulaşılmasında anahtar role sahiptir. Svirydzenka (2016) finansal sistemdeki gelişme ile birlikte hem fiziki hem de beşerî sermaye artmakta hem de toplam faktör verimliliği yükselmektedir. Zira finansal sistemin gelişmesi sermaye maliyetini düşürürken, sermayeye ulaşmayı kolaylaştırır ve finansman için ayrılan zamandan kazanılarak zaman tasarrufu yapmaya imkân tanır. Levine (1997) finansal piyasaların yatırım için daha iyi fırsatların tanınmasını, üretim maliyetlerinin düşmesini, vatandaşların tasarruflarının artmasını, inovasyon teknolojilerinin teşvik edilmesini ve yatırımlarında risk alan yatırımcıların sayısının artmasını sağladığını kabul etmektedir.

Levine (2005) bir başka çalışmasında finansal sektörün ekonomi üzerinde beş temel etkisinin olduğunu vurgulamaktadır. Ona göre finansal sektörün ilk etkisi uygulanabilir yatırımlar hakkında bilgi vermesidir. Daha sonrasında yatırım finanse edildikten sonra kurumsal yönetimler tarafından yatırımların denetlenmesi sağlanmaktadır. Böylece bir anlamda yatırım öncesi ve sonrasında sırasıyla ters seçim ve ahlaki tehlike problemlerinin ortaya çıkmasını önlemektedir. Dahası ekonomide ticaretin, çeşitlendirmenin ve risk yönetiminin artmasını sağlamaktadır. Son olarak tasarruf ortaklığ1 görevini yerine getirirken, mal ve hizmet ticaretini kolaylaştırmaktadır.

Finansal sistemin gelişmişliği farklı rasyolar tarafından ölçülürken, Sahay (2015) finansal gelişmişlik kavramının üç temel bileşeninin olduğunu vurgulamıştır. Bunlar derinlik, etkinlik ve erişimdir. Bu bileşenlerden derinlik özellikle gelişmekte olan ülkeler açısından önemli bir yere sahiptir. Zira, derinlikten kastedilen finansal piyasaların büyüklüğü ve likiditesidir. Finansal derinlik ölçülürken sistemin kendisinden çok bir ekonomide toplanan finansal varlıkların büyüklüğü ölçülmektedir (Gezer, 2018, s.96). Bir ekonomide finansal varlık arzı arttıkça varlıkların kalitesinin çeşitliliği artar, yeni borçlanıcılar piyasaya katılır ve finansal piyasalar daha da 
gelişir (Shaw, 1973, s.7). Böylece finansal derinlik arttıkça yatırımlar artar ve ekonomik büyüme daha da hızlanır.

Yiğitbaşı'na (2017) göre bir ekonomideki finansal derinlik tasarruflar açısından da önem taşımaktadır. Bu bağlamda ekonomik büyümenin desteklenmesi için finansal derinliğin özellikle gelişmekte olan ülkelerde önemli bir faktör olduğunu söylemek mümkündür.

Finansal derinliğin ölçülmesi ile ilgili çalışmalar incelendiğinde, Lynch (1996) tarafından yapılan çalışmada farklı kriterler kullanıldığı görülmektedir. Araştırmacı çalışmasında finansal derinliği ölçen göstergeleri beş kategoride gruplandırmıştır. Bunlardan ilki miktar ölçüleridir. Bu kategoride M1 ve M2 gibi parasal büyüklükler ile özel sektöre verilen kredilerin gayrisafi yurtiçi hasılaya oranı bulunmaktadır. İkinci kategori yapısal ölçülerden oluşmaktadır. Bu kategoride M2/M1 rasyosu gibi rasyolar değerlendirilmektedir. Üçüncü kategoride finansal fiyatlar bulunmaktadır ki, bu kategoriye reel mevduat faiz oranı örnek gösterilebilir ve finansal derinleşmenin ortaya çıkabilmesi için bu faiz oranlarının pozitif olması gerekmektedir. Dördüncü kategori ürün çeşitliliğidir. Piyasada finansal ürün miktarının artması finansal sektörün daha fazla kullanılmasına neden olurken risk daha kolay fiyatlandırılabilir. Burada üründen kastedilen hazine bonosu, future ve swap gibi araçlardır. Son kategori ise işlem maliyetleridir. Optimal derinliğin sağlanabilmesi için finansal sistemde düşük işlem maliyeti gerekmektedir. Bu maliyetlere banka işlem masrafı ve faiz oranı spreadi örnek gösterilebilir (Yiğitbaş, 2017, s.510).

Eichengreen (1997) finansal entegrasyonun finansal derinliğe neden olacağını, zira daha aktif, likit ve etkin yerel finansal piyasaların oluşmasına neden olacağını ileri sürmektedir. Daha derin finansal piyasalar ise daha fazla yatırıma cesaret verirken ekonomik büyümeyi destekleyecektir. Mirdala (2011) yabancı sermaye girişinin yoğun olduğu ekonomilerde bu durumun, sermaye piyasalarındaki ve kredi piyasalarındaki orantısız büyümeden anlaşılabileceğini iddia etmiştir.

Söz konusu teorik açıklamalar 1şığında, gelişmekte olan ülkeler arasında yabancı sermaye girişi yoğun ekonomilerde finansal derinleşmenin gerçekten ekonomik büyüme üzerinde etkili olup olmadığını ampirik olarak test etmenin faydalı olacağı açıktır. Zira 1980'li yıllarda tüm dünyada başlayan küresel finans sistemine entegrasyon hareketi birçok gelişmekte olan ülkenin de bu akıma dahil olmasına neden olmuştur. Bu ülkeler 
arasında Türkiye, Brezilya, Hindistan, Güney Afrika ve Endonezya da bulunmaktadır.

Yukarıda sayılan ekonomilerin bir diğer özelliği ise küresel finans krizi sonrasında Amerika Birleşik Devletleri Merkez Bankası'nın "miktarsal genişleme" politikasının bitişi sonrası finansal sistemlerindeki kırılganlıkların artmış olmasıdır. Bu nedenle bu beş ülkeye "Kırılgan Beşli" lakabı takılmıştır. Kırılganlığın temelinde ise bu piyasaların yabancı sermayeye bağımlılı̆̆ bulunmaktadır. Zira miktarsal genişleme politikasının bitmesi ile gelişmekte olan ülkelerde bulunan yabancı sermaye Amerika Birleşik Devletleri'ne doğru çıkış yapmıştır.

Tüm bu açıklamalar ışığında, bu çalışmada kırılgan beşli ülkelerinde finansal derinleşmenin ekonomik büyüme üzerindeki muhtemel etkilerinin ne olduğunu 1980 ve 2018 yılları arasında kalan dönemde panel veri analiz yöntemleri ile test edilmektedir. Bahsedilen ülkelerde yabancı sermayenin finansal derinlik üzerinden olumlu etkileri ile kırılganlığa bağlı olumsuz etkileri karşılaştırıldığında hangi tarafın daha ağır bastığı yapılan ampirik çalışma ile ortaya çıkarılmaya çalışılacaktır. Bu bağlamda çalışmanın ele alınan ülkeler ve bakış açısı ile literatüre katkı yapacağı düşünülmektedir.

Çalışmanın ikinci bölümünde kırılgan beşli ülkelerine ait ekonomik büyüme ve finansal sisteme ait göstergeler incelenmektedir. Böylece ampirik analiz öncesinde ekonomilerdeki gelişmeler grafiksel olarak yorumlanacaktır. Bir sonraki bölümde konu ile ilgili literatür özetlenmektedir. Böylece mevcut çalışmalar ile elde edilen bulgular karşılaştırılabilecektir. Dördüncü bölümde ampirik analize ait bilgiler paylaşılmaktadır. Burada ele alınan model, değişkenler ve ampirik analiz sonuçları sunulmaktadır. Son bölümde ise sonuçlar yorumlanarak politika çıkarsamaları yapılmaktadır.

\section{Kırılgan Beşli Ekonomilerinde Ekonomik Büyüme ve Finansal Derinlik}

"Kırılgan beşli" lakabı dış şoklara duyarlılık ve ekonomilerinin kırılganlık seviyelerinden dolayı aralarında Brezilya, Hindistan, Türkiye, Endonezya ve Güney Afrika'nın bulunduğu beş ülkeye Goldman and Sachs tarafından 2013 yılında takılmıştır (Kayhan vd., 2017, s.318). Bu ülkeler 
incelendiğinde yüksek dış borç, finansal kırılganlık ve cari açık gibi ortak problemlerinin olduğu görülmektedir.

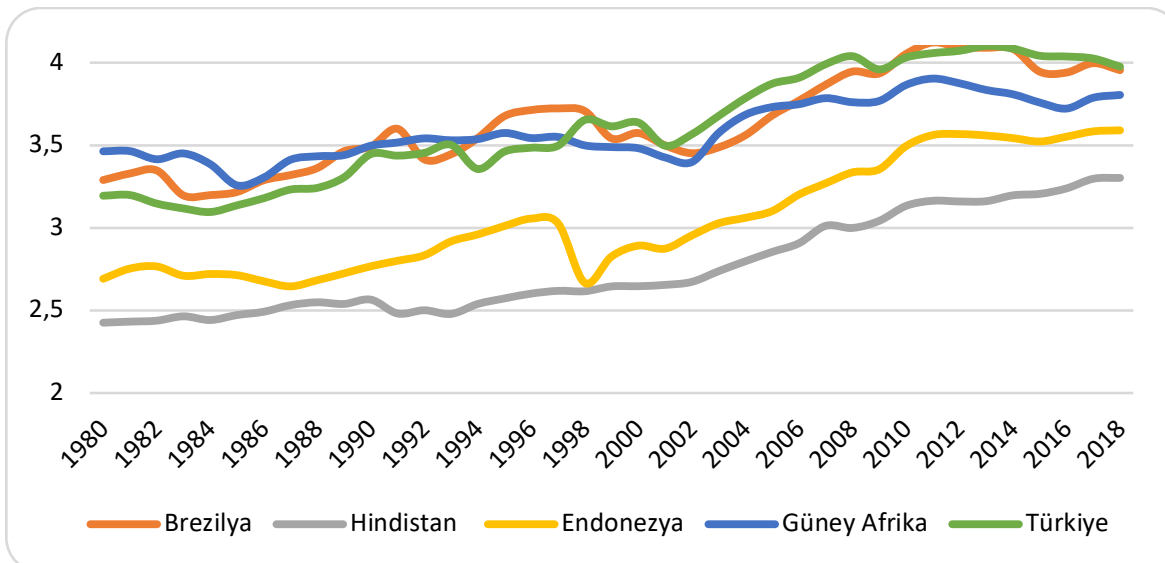

Grafik 1. Kişi Başı Gayrisafi Yurtiçi Hasıla Gelişimi

Kaynak: Dünya Bankası, Dünya Gelişim Göstergeleri.

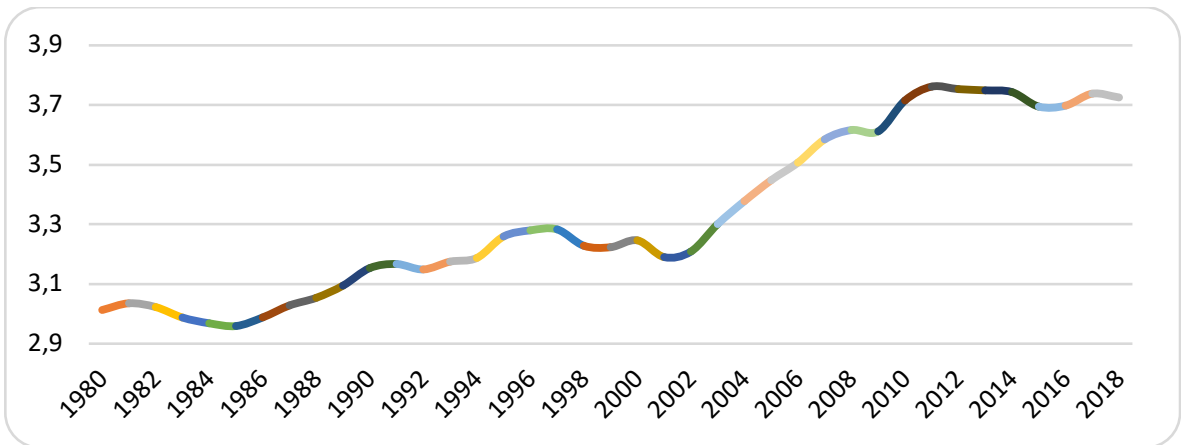

Grafik 2. Kişi Başı Gayrisafi Yurtiçi Hasılanın Aritmetik Ortalaması

Kaynak: Dünya Bankası, Dünya Gelişim Göstergeleri.

Grafik 1'de doğal logaritması alınmış bir şekilde kırılgan beşli ülkelerine ait kişi başı yurtiçi hasıla ve Grafik 2' de yıllar itibariyle kişi başı gayrisafi yurtiçi hasılaların aritmetik ortalamaları yer almaktadır. Kişi başı gayrisafi yurtiçi hasılanın en yüksek olduğu yılların Brezilya ve Güney Afrika'da 2011, Hindistan ve Endonezya' da 2018, Türkiye'de ise 2013 yılı olduğu görülmektedir. Öte yandan kişi başı gayrisafi yurtiçi hasılanın en düşük olduğu yıllar Brezilya'da 1984, Hindistan'da 1980, Endonezya'da 
1987, Güney Afrika'da 1985, Türkiye'de ise 1984 yılıdır. Kişi başı gelir açısından kırılgan beşli ülkeleri içerisinde en düşük gelir seviyesine sahip olan ülke Hindistan ve en yüksek gelir seviyesine sahip olan ülke ise Brezilya, Güney Afrika ve Türkiye arasında değişmektedir. Ancak en istikrarlı büyüme trendine sahip olan ülkenin Hindistan olduğu görülmektedir. Çünkü Endonezya'nın 1997, Brezilya, Güney Afrika ve Türkiye ekonomilerinin 1998-2000 döneminde yaşadıkları makro ekonomik krizler kişi başı gelir seviyesinde önemli kırılmaların meydana gelmesine neden olmuştur.

Grafik 1'in analizi sonrasında ortaya çıkan bir başka sonuç Brezilya, Güney Afrika ve Türkiye ekonomilerinin uzun dönemde eş-bütünleşik oldukları ve olası muhtemel bir şekilde yatay kesit bağımlılığına sahip olma ihtimalidir. Gerek seviye gerekse değişim açısından birbirlerine benzer bir hareket içerisinde oldukları söylenebilir.

Kişi başı gelirin aritmetik ortalamalarının olduğu Grafik 2' de ise ampirik analiz periyodunun başladığ 1980 yılı ve bitiş yılı olan 2018 verilerine bakıldığında açık bir şekilde büyüme trendinin olduğu görülmektedir. Ancak söz konusu büyüme trendi 1981-1985 ve 1996-2002 dönemlerinde sekteye uğramıştır. 2012-2018 dönemi sonrasında ise yatay - aşağ1 yönlü bir ortalamanın ortaya çıktığı söylenebilir.

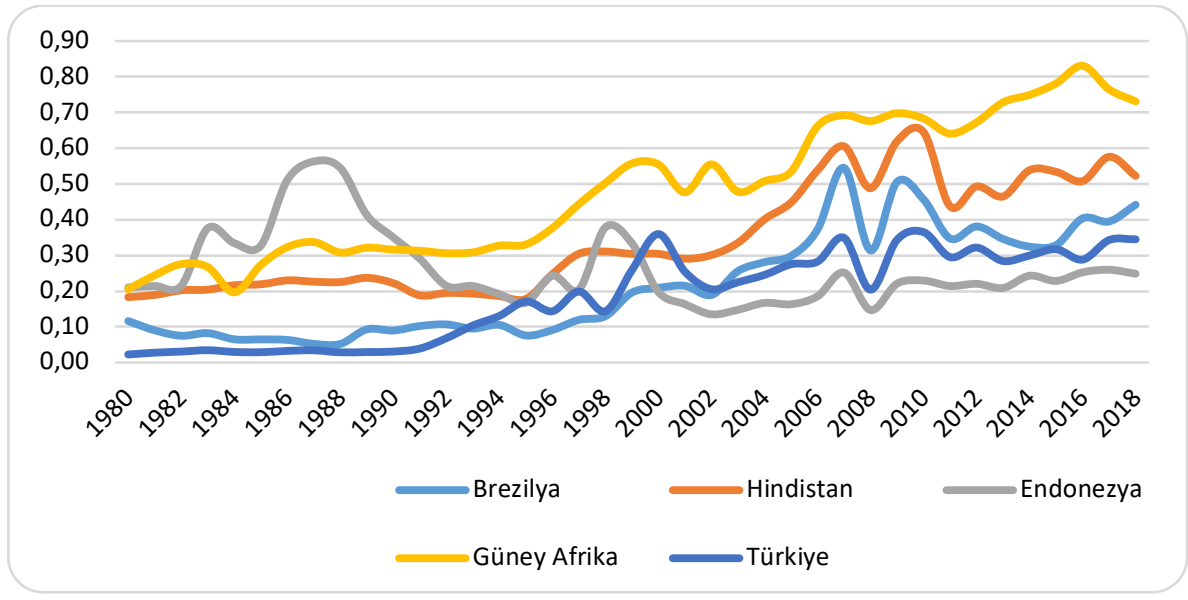

Grafik 3. Finansal Derinliğin Gelişimi

Kaynak: Dünya Bankası, Dünya Gelişim Göstergeleri. 


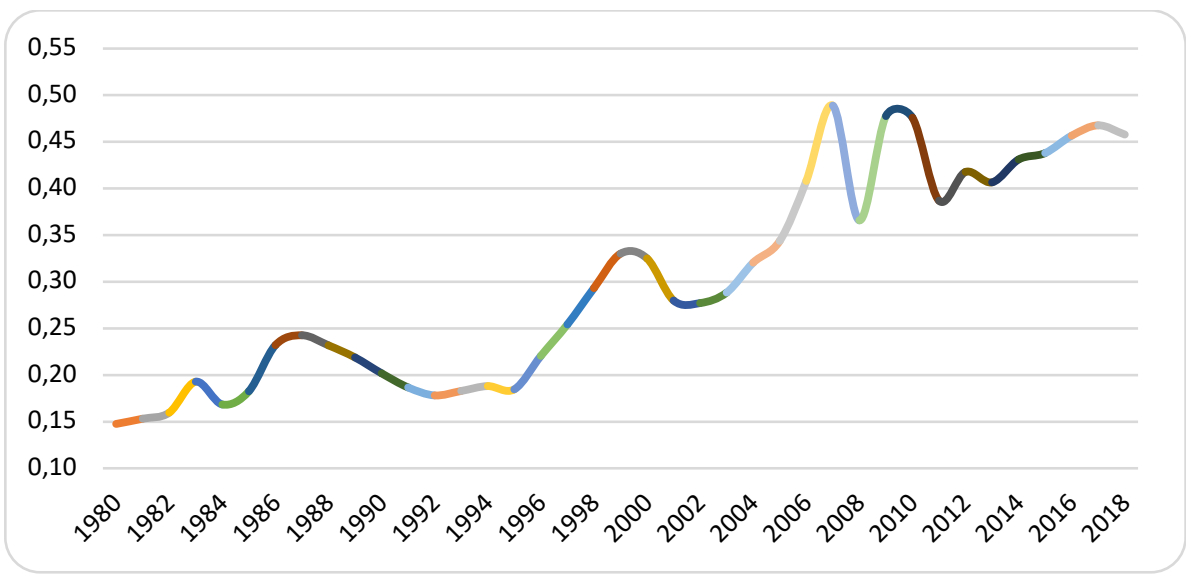

Grafik 4. Finansal Derinliğin Aritmetik Ortalaması

Kaynak: Dünya Bankası, Dünya Gelişim Göstergeleri.

Grafik 3'te ise kırılgan beşli ülkelerindeki finansal piyasa derinliği yer almaktadır. Yıllık verilerin sunulduğu grafik incelendiğinde, 1980-1991 yılları arasında Endonezya'nın finans piyasalarında en yüksek derinlik seviyesine sahip olduğu ancak 1992 yılından itibaren Güney Afrika ekonomisinin öne geçtiği görülmektedir. Endonezya ekonomisinde 1998 yılında yaşanan ekonomik kriz ile birlikte finansal derinlik konusunda önemli kayıplar yaşandığı ve ülkenin kırılgan beşli ekonomileri içerisinde en düşük finansal derinliğe sahip olduğu görülmektedir.

Finansal piyasa derinliğinin en yüksek olduğu dönem Brezilya'da 2007, Hindistan ve Türkiye'de 2010, Endonezya'da 1987, Güney Afrika'da 2016 yılıdır. Buna karşın finansal piyasa derinliğinin en düşük olduğu dönem Brezilya'da 1987, Hindistan'da 1995, Endonezya'da 2008, Güney Afrika ve Türkiye'de 1980 yılıdır. Kırılgan beşli ülkelerinin küresel piyasalara entegrasyonu ile birlikte dışsal şoklardan ne derece etkilendiği ise Grafik 4'te görülmektedir. Finansal derinlik, küresel para arzı ve finansal enstrüman çeşitliliği artmış olmasına rağmen 1986, 1999, 2007 ve 2009 tarihlerinde kayda değer düşüşler yaşanmıştır. Ancak finansal derinlik endeksinin başlangıç ve bitiş noktaları göz önüne alındığında, kişi başı gayrisafi yurtiçi hasılada olduğu gibi büyüme trendine sahip olduğu görülmektedir. 


\section{Literatür Özeti}

Finansal piyasalar ile ekonomik büyüme arasındaki ilişki, literatürde farklı açlardan incelenmiştir. Bu çalışmaların önemli bir kısmı finansal sistemin gelişmişliği ile ekonomik büyüme performansı arasındaki ilişkiyi incelerken, finansal baskınlık, derinlik ve benzeri ölçütlerin ekonomi, cari açık, döviz kuru ve yatırım gibi makroekonomik değişkenler üzerindeki etkilerini inceleyen çalışmalar da bulunmaktadır.

Konu ile ilgili öncül çalışmalar finansal sistemin büyümesi ile ekonomik büyüme arasındaki ilişkiyi incelemiştir. Calderon'un (2002) yapmış olduğu kapsamlı çalışma bunlardan bir tanesidir. Araştırmacı çalışmasında 109 gelişmiş ve gelişmekte olan ülke ekonomisini incelemiştir. Nedensellik analiz yöntemlerini kullanan yazar, genel olarak finansal gelişmenin ekonomik büyümeye öncülük ettiği sonucuna ulaşmıştır.

Abu - Bader ve Abu Quarn (2006) yaptıkları çalışmalarında beş adet MENA ülkesini ele almıştır. 1960- 2004 yılları arasında kalan döneme ait verileri eş-bütünleşme, VAR ve hata düzeltme metotları ile test eden yazarlar iki değişken arasında zayıf bir ilişkinin olduğunu, ekonomik büyüme ve finansal gelişme arasında uzun dönemde bir ilişkinin zamanla ortaya çıktığını söylemektedirler.

Apergis vd. (2007) finansal gelişmişlik ve ekonomik büyüme arasındaki ilişkiyi altmış beş ülke verisini kullanarak 1975- 2000 dönemi için test etmişlerdir. Panel veri eş-bütünleşme analiz metodu ile elde ettikleri sonuç finans ve büyüme ilişkisinin uzun dönemde ortaya çıktığını göstermektedir.

Şengül (2020) finansal sistemin ekonomik büyüme üzerindeki etkisini farklı bir açıdan incelemiş ve finansal baskınlığın Türkiye ekonomisinin büyüme performansı üzerindeki etkisini ampirik olarak test etmiştir. Sonuçlar göstermektedir ki; finansal baskınlık Türkiye ekonomisinin büyümesini uzun dönemde etkilemektedir.

Finansal baskınlığı ele alan çalışmalara bir diğer örnek ise Etibar vd. ‘nin (2019) çalışmasıdır. On dokuz ekonomiyi 1973 yılından 2017 yılına kadar inceleyen yazarlar panel veri ekonometrisini kullanırken, sonuçlar ülke grubu bazında ekonomik büyüme üzerinde finansal baskınlığın önemli bir problem olduğunu ve muhtemel bir finansal sıkılaşmanın ekonomik büyüme üzerinde negatif etkisinin olabileceğini göstermiştir. 
Doğan (2019) ise finansal baskınlığın ekonomik büyüme üzerindeki etkisini test eden çalışmasında Türkiye, Brezilya, Meksika ve Arjantin ekonomilerinde finansal sistemde yaşanan bir problemin ekonomi üzerinde ne derece etkili olduğunu incelemiştir. 2000 ve 2018 yılları arasında geçen süreyi inceleyen yazar, finansal baskınlığın ekonomide olumsuzluğa neden olduğunu ve gayrisafi yurtiçi hasılada düşüşe neden olduğunu belirtmiştir.

Finansal derinlik ile ilgili literatürde bir dizi çalışma bulunmaktadır. Bunlardan bir tanesi de Gezer'e (2018) aittir. Gezer (2018) panel veri bootstrapa dayalı analiz sonucunda, incelenen on dört gelişmiş ülkenin birçoğunda çift yönlü nedenselliğin var olduğunu tespit etmiştir.

Özşahin ve Uysal (2017) finansal derinleşme ile ekonomik büyüme ilişkisini on iki MENA ülkesi için incelemiştir. 2000- 2014 dönemi için Emirmahmutoğlu ve Köse (2011) panel nedensellik testini kullanarak yaptıkları analizin sonucunda, finansal derinliğin farklı ölçütleri üzerinden dokuz ülkede finansal derinlikten ekonomik büyümeye doğru bir nedensellik ilişkisinin olduğunu bulmuşlardır.

Agheli ve Hadian (2017) finansal derinlik - ekonomik büyüme ilişkisini on beş seçilmiş gelişmekte olan ülke ve Ortadoğu ülkesi için test etmişlerdir. 1980- 2013 dönemi için ilişkiyi bootstrap panel data metodu ile test eden yazarlar finansal gelişmenin ekonomik büyümeyi yeterince etkileyemediği, zira finansal sistemin derinliğinin yetersiz olduğu sonucuna ulaşmişlardır.

Pradhan (2010) 1970- 2007 döneminde Hindistan ekonomisinde finansal derinleşme, doğrudan yabancı sermaye ve ekonomik büyüme arasındaki ilişkiyi incelemiştir. Değişkenler arasında eş-bütünleşme ilişkisinin olduğuna dair kanıtlar ede edilirken finansal derinleşme ile doğrudan yabancı sermaye girişi arasında, finansal derinleşmeden sermaye girişlerine doğru tek yönlü bir nedenselliğin olduğu tespit edilmiştir. Dahası ekonomik büyüme ile doğrudan yabancı sermaye yatırımları arasında da çift yönlü bir nedenselliğin olduğu sonucuna ulaşılmıştır.

Mirdala (2011) geçiş ekonomilerini incelediği çalışmasında 2000- 2010 yılları arasında finansal derinleşmenin ekonomiler üzerindeki etkisini test etmiştir. Çalışmada Granger nedensellik ve vektör hata düzeltme modellerini kullanmış ve finansal derinleşmenin özellikle düşük gelir 
grubundaki ülkelerde ekonomik büyüme üzerinde etkili olduğu ve bu etkinin de kısa dönemde geçerli olduğu sonucuna ulaşmıştır.

Görüldüğü gibi finansal sistemin ekonomi üzerindeki etkileri farklı açılardan incelenmektedir. Bununla birlikte finansal derinleşmenin ekonomi üzerindeki etkilerinin incelendiği çalışmalarda genel olarak derinleşmenin artmasının, ekonomik büyümeyi arttırdığı sonucuna ulaşılmıştır. Bununla birlikte finansal derinliğin etkili olabilmesi için de finansal gelişmişliğin belirli bir düzeyde olması gerektiği anlaşılmaktadır. Bu bağlamda kırılgan beşli ekonomilerinin gelişmişliğinin yeterli olup olmadığ 1 da bir sonraki bölümde yapılan ampirik analizler ile tespit edilmeye çalışılacaktır.

\section{Ampirik Sonuçlar}

Bu çalışmada Brezilya, Hindistan, Endonezya, Güney Afrika ve Türkiye ekonomilerinde 1980-2018 dönemine ait finansal piyasa derinlik endeksi (FDI) ve Amerikan doları cinsinden cari kişi başı gayrisafi yurtiçi hasıla (GDPPC) arasındaki ilişki analiz edilmiştir. Finansal piyasa derinlik endeksi Uluslararası Para Fonu veri tabanından ve kişi başı gayrisafi yurtiçi hasıla ise Dünya Bankası veri tabanından elde edilmiştir. Değişen varyans sorununa karşı kişi başı gayrisafi yurtiçi hasılanın doğal logaritması alınmıştır. İlk olarak finansal piyasa derinliği ile kişi başı gayrisafi yurtiçi hasıla arasındaki korelâsyonlar Tablo 1'de gösterilmektedir.

Tablo 1. Finansal Derinlik ve Kişi Başı Gayrisafi Yurtiçi Hasıla Arasındaki Korelâsyon

\begin{tabular}{lll}
\hline & FDI & GDPPC \\
\hline FDI & 1 & - \\
GDPPC & 0.23 & 1 \\
\hline
\end{tabular}

Finansal piyasa derinliği ile kişi başı gayrisafi yurtiçi hasıla arasında pozitif fakat düşük dereceli bir korelasyon bulunmaktadır. Bu öncül sonuç finansal piyasaların derinleşmesi ile ekonomik büyüme arasında muhtemel bir ilişkinin olabileceğine dair ipuçları vermektedir. Bununla birlikte sadece korelasyon katsayıları üzerinden nihai bir sonuca ulaşmak mümkün değildir. 
Kırılgan beşli olarak adlandırılan ülkelerin makro ekonomik yapıları birbirine benzemektedir. Bu husus panel veri literatüründe yatay kesit ba-

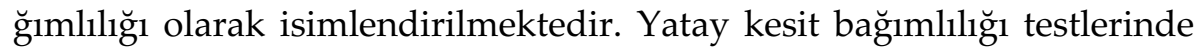
temel hipotez paneldeki ülkelerde yatay kesit bağımlılığının yer almadığ ve alternatif hipotez ise paneldeki ülkelerde yatay kesit bağımlılı̆̆ının olduğu şeklindedir. Analiz sonuçları Tablo 2'de özetlenmektedir.

Tablo 2. Yatay Kesit Bağımlılı̆̆ı Test Sonuçlan

\begin{tabular}{|c|c|c|c|c|}
\hline \multirow[t]{3}{*}{ Sabitli Model } & \multicolumn{2}{|l|}{ FDI } & \multicolumn{2}{|l|}{ GDPPC } \\
\hline & Test İstatistiği & Olasılık & Test İstatistiği & Olasilık \\
\hline & & Değeri & & Değeri \\
\hline$C D_{l m}(\mathrm{BP}, 1980)$ & 42.468 & $0.00^{* * *}$ & 32.007 & $0.00^{* * * *}$ \\
\hline$C D_{l m}$ (Pesaran, 2004) & 7.260 & $0.00^{* * *}$ & 4.921 & $0.00^{* * *}$ \\
\hline$C D \quad($ Pesaran, 2004) & -4.204 & $0.00^{* * *}$ & -3.899 & $0.00^{* * *}$ \\
\hline$L M_{a d j}(\mathrm{PUY}, 2008)$ & 4.870 & $0.00^{* * *}$ & 11.520 & $0.00^{* * *}$ \\
\hline
\end{tabular}

Not: Gecikme sayısı ( $\left.p_{i}\right) 1$ olarak alınmıştır. ${ }^{* * *},{ }^{* *}$ ve ${ }^{*}$ değerleri sırasıyla \%1 (0.01), \%5 (0.05) ve \%10 (0.1) anlam seviyelerinde alternatif hipotezin kabul edildiğini göstermektedir.

Tablodaki sonuçlara göre, olasılık değerleri hem finansal piyasa derinliği hem de kişi başı gayrisafi yurtiçi hasıla değişkenleri için paneli oluşturan kırılgan beşli ülkeleri açısından birbirine benzer yapılar bulunduğunu göstermektedir. Bu nedenle ikinci nesil panel birim kök testlerine başvurulmalıdır. Smith vd. (2004) tarafından geliştirilen panel birim kök testinde "bootstrap" yöntemi ile kritik değerler elde edilebilmektedir. Smith vd. (2004) panel birim kök testinde, temel hipotez değişkenin birim kök taşıdığını ve alternatif hipotez ise değişkenin birim kök taşımadığını iddia etmektedir.

Tablo 3. Smith vd. (2004) Panel Birim Kök Test Sonuçları

\begin{tabular}{lllll}
\hline & Sabitli Model & & \multicolumn{2}{c}{ Sabitli ve Trendli Model } \\
Düzey & Test İstatistiği & $\begin{array}{l}\text { Bootstrap } \\
\text { Olastlı Değeri }\end{array}$ & Test İstatistiği & $\begin{array}{l}\text { Bootstrap } \\
\text { Olas1lı Değeri }\end{array}$ \\
\hline FDI & -1.050 & 0.842 & -2.472 & 0.222 \\
GDPPC & -0.454 & 0.981 & -2.042 & 0.605 \\
\hline Birinci Fark & & & & \\
FDI & -6.974 & $0.00^{* * *}$ & -6.880 & $0.00^{* * *}$ \\
GDPPC & -5.064 & $0.00^{* * *}$ & -5.123 & $0.00^{* * *}$ \\
\hline
\end{tabular}


Not: Maksimum gecikme uzunluğu 4 olarak alınmış ve optimal gecikme uzunlukları genelden özele (general-to-specific) yaklaşımı ile belirlenmiştir. Olasıllk değerleri 5000 bootstrap dağılımından elde edilmiştir. ***.* ve * değerleri strastyla \%1 (0.01), \%5 (0.05) ve \%10 (0.1) anlam seviyelerinde alternatif hipotezin kabul edildiğini göstermektedir.

Elde edilen sonuçlara göre hem finansal piyasa derinliği hem de kişi başı gayrisafi yurtiçi hasıla değişkenleri düzey değerlerinde birim kök taşımaktadır. Yine her iki değişkenin birinci farkları alındığında durağan olduğu görülmektedir. Bu durumda analizlerin sağlıklı bir şekilde yapılabilmesi için değişkenlerin birinci farklarının analize dahil edilmesi gerekmektedir.

Tablo 4. Yatay Kesit Bağımlılı̆̆ı ve Homojenite Test Sonuçlan

\begin{tabular}{|c|c|c|}
\hline & İstatistik & Olasılık Değeri \\
\hline \multicolumn{3}{|l|}{ Yatay Kesit Bağımlılı̆̆ı: } \\
\hline$L M(\mathrm{BP}, 1980)$ & 57.414 & $0.00^{* * *}$ \\
\hline$C D_{l m}($ Pesaran, 2004) & 10.602 & $0.00^{* * *}$ \\
\hline$C D \quad$ (Pesaran, 2004) & 7.193 & $0.00^{* * *}$ \\
\hline$L M_{a d j}(\mathrm{PUY}, 2008)$ & 47.907 & $0.00^{* * *}$ \\
\hline \multicolumn{3}{|l|}{ Homojenite: } \\
\hline$\tilde{\Delta}$ & 21.597 & $0.00^{* * *}$ \\
\hline$\tilde{\Delta}_{a d j}$ & 22.456 & $0.00^{* * *}$ \\
\hline
\end{tabular}

$G D P P C_{i t}=\alpha_{i}+\beta_{1 i} F D I_{i t}+\varepsilon_{i t}$ modelinde kişi başı gayrisafi yurtiçi hasıla bağımlı değişken ve finansal piyasa derinliği ise bağımsız değişkeni ifade etmektedir. Bu modeli oluşturan paneldeki ülkelere ait eğim parametrelerinin birbirinden farklı olduğu sonucuna ulaşılmaktadır. Grafik 1 ve Grafik 3 'ten de görüleceği üzere kişi başı gelir açısından Endonezya ve Hindistan ekonomilerinin, finansal derinlik açısından ise Endonezya ve Güney Afrika ekonomilerinin panelden ayrı bir şekilde hareket ettikleri göze çarpmaktadır. 
Tablo 5. LM Bootstrap Panel Eşbütünleşme Test Sonuçları

\begin{tabular}{|c|c|c|c|c|c|c|}
\hline & \multicolumn{2}{|c|}{ Sabitli Model } & \multicolumn{4}{|c|}{ Sabitli ve Trendli Model } \\
\hline & & Asimptotik & $\begin{array}{l}\text { Boot- } \\
\text { strap }\end{array}$ & & Asimptotik & $\begin{array}{l}\text { Boot- } \\
\text { strap }\end{array}$ \\
\hline & & Olasilik & Olasılık & & Olasilık & Olasilik \\
\hline & İstatistik & Değeri & Değeri & İstatistik & Değeri & Değeri \\
\hline$L M_{N}^{+}$ & 5.141 & 0.284 & $0.00^{* * *}$ & 6.694 & $0.012^{* *}$ & $0.00^{* * *}$ \\
\hline
\end{tabular}

Not: Sıfır hipotezi eşbütünleşme yok şeklindedir. Bootstrap olasılık değerleri 1.000 tekrarlı dă̆llımdan elde edilmiştir. Asimptotik olasılık değgerleri, standart normal dă̆ılımdan elde edilmiştir. ${ }^{* *},{ }^{* *}$ ve ${ }^{*}$ değgerleri strasıla \%1 (0.01), \%5 (0.05) ve \%10 (0.1) anlam seviyelerinde alternatif hipotezin kabul edildiğini göstermektedir.

LM bootstrap eş-bütünleşme testine göre sabitli modelde asimptotik olasılık değerine göre kişi başı gayrisafi yurtiçi hasıla ve finansal piyasa derinliği arasında uzun dönemli ilişki bulunmamaktadır. Ancak sabitli modelde bootstrap olasıllk değerine göre $\% 1$ anlam seviyesinde, sabitli ve trendli modelde asimptotik olasılık değerine göre $\% 5$ anlam seviyesinde ve bootstrap olasılık değerine göre $\% 1$ anlam seviyesinde göre kişi başı gayrisafi yurtiçi hasıla ve finansal piyasa derinliği arasında uzun dönemli ilişki bulunmaktadır. Panel vektör otoregresyon (PVAR), panel hata düzeltme modeli (PVECM) $\phi_{1 i} \hat{\varepsilon}_{i t-1}$ ve $\phi_{2 i} \hat{\varepsilon}_{i t-1}$ hata düzeltme katsayısı ise;

$$
\begin{aligned}
& \triangle F D I=\delta_{1 i}+\sum_{p=1}^{k} \delta_{11 i p} \Delta F D I_{i t-p}+\sum_{p=1}^{k} \delta_{12 i p} \Delta G D P P C_{i t-p}+\phi_{1 i} \hat{\varepsilon}_{i t-1}+v_{1 i t} \\
& \triangle G D P P C=\delta_{2 i}+\sum_{p=1}^{k} \delta_{21 i p} \Delta G D P P C_{i t-p}+\sum_{p=1}^{k} \delta_{22 i p} \Delta F D I_{i t-p}+\phi_{2 i} \hat{\varepsilon}_{i t-1}+v_{2 i t}
\end{aligned}
$$

regresyonları kurulmaktadır. Birinci regresyonda temel hipotez PVAR'da kısa dönemde $\sum_{p=1}^{k} \delta_{12 i p} \Delta G D P P C_{i t-p}=0$ ve PVEC'te uzun dönemde $\phi_{1 i} \hat{\varepsilon}_{i t-1}=0$ kişi başı gayrisafi yurtiçi hasıladan finansal piyasa derinliğine doğru Granger nedensellik yoktur hipotezini test etmektedir. Alternatif hipotezde PVAR'da kısa dönemde $\sum_{p=1}^{k} \delta_{12 i p} \triangle G D P P C_{i t-p} \neq 0$ ve PVEC'te uzun dönemde $\phi_{1 i} \hat{\varepsilon}_{i t-1} \neq 0$ kişi başı gayrisafi yurtiçi hasıladan finansal piyasa derinliğine doğru Granger nedensellik vardır hipotezini test etmektedir. Diğer regresyonda temel hipotez PVAR'da kısa dönemde 
$\sum_{p=1}^{k} \delta_{22 i p} \Delta F D I_{i t-p}=\mathrm{o}$ ve PVEC'te uzun dönemde $\phi_{2 i} \hat{\varepsilon}_{i t-1}=0$ finansal piyasa derinliğinden kişi başı gayrisafi yurtiçi hasılaya doğru Granger nedensellik yoktur hipotezini test etmektedir. Alternatif hipotezde PVAR'da kısa dönemde $\sum_{p=1}^{k} \delta_{22 i p} \Delta F D I_{i t-p} \neq 0$ ve PVEC'te uzun dönemde $\phi_{2 i} \hat{\varepsilon}_{i t-1} \neq 0$ finansal piyasa derinliğinden kişi başı gayrisafi yurtiçi hasılaya doğru Granger nedensellik vardır hipotezini test etmektedir.

Tablo 6. Panel VAR ve VECM Nedensellik Testleri

\begin{tabular}{llll}
\hline & \multicolumn{2}{l}{ Kisa Dönem Nedensellik (PVAR) } & Uzun Dönem Nedensellik (PVECM) \\
\hline & $\Delta($ GDPPC $)$ & $\Delta($ FDI $)$ & ECT $(-1)$ \\
$\Delta$ (GDPPC $)$ & - & $3.940(0.047)^{* *}$ & $-0.064[-2.359]^{* * *}$ \\
$\Delta$ (FDI) & $5.737(0.016)^{* *}$ & - & $0.042[1.727]^{* *}$ \\
\hline
\end{tabular}

Not: () olasılık değerlerini, [] t istatistiklerini göstermektedir. ${ }^{* * *}{ }^{* *}$ ve ${ }^{*}$ değgerleri sırasıyla $\% 1(0.01), \% 5$ (0.05) ve \%10 (0.1) anlam seviyelerinde alternatif hipotezin kabul edildiğini göstermektedir.

Kısa dönemde kişi başı gayrisafi yurtiçi hasıla ve finansal piyasa derinliği arasında \%5 anlam seviyesinde karşılıklı nedensellik bulunmaktadır. Benzer bulguların uzun dönemde de geçerli olduğu görülmektedir. $\mathrm{Bu}$ sonuçlar finansal derinliğin bu ülke ekonomilerinin büyüyebilmesi için önemli olduğu anlamına gelmektedir. Dahası ekonomi büyüdükçe finansal derinlik de artmaktadır. Zira büyüme ile ekonomideki likidite artarken bu da finansal sisteme giren fon miktarını artırarak sistemin hacmini artırmaktadır.

Elde edilen sonuçlardan çıkarılabilecek bir diğer sonuç ise, ele alınan ülkelerin kırılganlıkları hakkındadır. Şöyle ki, bu ekonomilerin ortak yönü olan kırılganlıklar yabancı sermayeden kaynaklanmaktadır ve sonuçlara göre bu kırılganlıkların getirmiş olduğu negatif etkinin finansal derinliğin pozitif etkisi ile bertaraf edilebilmiş olacağı görülmektedir. Bununla birlikte ele alınan sürenin uzunluğu dikkate alındığında söz konusu etkileşimin tam olarak anlaşılması da zor olabilir. Bu etkinin net bir şekilde incelenebilmesi için daha uzun dönem ve daha yüksek frekanslı veri kullanmak daha uygun olacaktır.

Analiz kapsaminda uygulanan bir diğer test ise Emirmahmutoğlu ve Köse (2011) tarafından geliştirilen panel nedensellik testidir. Bu testi diğer 
panel nedensellik testlerinden ayıran ise nedensellik ilişkisinin ülke bazlı sonuçlarına ulaşmaya imkan vermesidir. Emirmahmutoğlu ve Köse (2011) panel nedensellik testinde;

$$
\begin{aligned}
& \Delta G D P P C=\delta_{1 i}+\sum_{p=1}^{k+d_{\max }} \delta_{11 i p} \Delta G D P P C_{i t-p}+\sum_{p=1}^{k+d_{\max }} \delta_{12 i p} \Delta F D I_{i t-p}+v_{1 i t} \\
& \Delta F D I=\delta_{2 i}+\sum_{p=1}^{k+d_{\max }} \delta_{21 i p} \Delta F D I_{i t-p}+\sum_{p=1}^{k+d_{\max }} \delta_{22 i p} \Delta G D P P C_{i t-p}+v_{2 i t}
\end{aligned}
$$

$\mathrm{d}_{\max }$ maksimum durağanlık seviyelerini ifade etmektedir. Daha önce yapılan birim kök testinde kişi başı gayrisafi yurtiçi hasıla ve finansal piyasa derinliği değişkenlerinin birinci farkında durağan olduğu tespit edilmiştir. Regresyonlarda $\sum_{p=1}^{k+d_{\max }} \delta_{12 i p} \Delta F D I_{i t-p}=0$ finansal piyasa derinliğinden kişi başı gayrisafi yurtiçi hasılaya doğru doğru Granger nedensellik olmadığını ve $\sum_{p=1}^{k+d_{\max }} \delta_{22 i p} \Delta G D P P C_{i t-p}=0$ kişi başı gayrisafi yurtiçi hasıladan finansal piyasa derinliğine nedensellik olmadığı hipotezini test etmektedir. Test sonuçları ise tablo 7'de verilmektedir.

Emirmahmutoğlu ve Köse (2011) panel nedensellik testine göre \%1 anlam seviyesinde Güney Afrika ekonomisinde kişi başı gayrisafi yurtiçi hasıladan finansal piyasa derinliğine doğru nedensellik bulunmaktadır. Öte yandan \%5 anlam seviyesinde Brezilya ve Hindistan ekonomilerinde, $\% 1$ anlam seviyesinde Güney Afrika ekonomisinde finansal piyasa derinliğinden kişi başı gayrisafi yurtiçi hasılaya doğru nedensellik bulunmaktadır.

Tablo 7. Emirmahmutoğlu ve Köse (2011) Panel Nedensellik Test Sonuçları

\begin{tabular}{llllll}
\hline Ülke & Gecikme & \multicolumn{2}{c}{ GDPPC $\neq>$ FDI } & \multicolumn{2}{l}{ FDI $\neq>$ GDPPC } \\
& & Wald & $\begin{array}{l}\text { Olasıllk } \\
\text { Değeri }\end{array}$ & Wald & $\begin{array}{l}\text { Olasilı } \\
\text { Değeri }\end{array}$ \\
\hline Brezilya & 1 & 0.042 & 0.835 & 6.215 & $0.012^{* *}$ \\
Hindistan & 1 & 0.193 & 0.659 & 5.093 & $0.024^{* *}$ \\
Endonezya & 1 & 1.462 & 0.226 & 0.538 & 0.463 \\
Güney Afrika & 3 & 18.639 & $0.00^{* * *}$ & 18.449 & $0.00^{* * *}$ \\
Türkiye & 1 & 0.201 & 0.653 & 0.412 & 0.520 \\
Fisher Stat. & & $\mathbf{2 1 . 0 7 6}$ & $\mathbf{0 . 0 2 0 ^ { * * }}$ & $\mathbf{3 4 . 9 2 6}$ & $\mathbf{0 . 0 0 ^ { * * * }}$ \\
\hline
\end{tabular}

Not: ${ }^{* *},{ }^{* *} v e^{*}$ değerleri sırasıyla $\% 1$ (0.01), \%5 (0.05) ve \%10 (0.1) anlam seviyelerinde alternatif hipotezin kabul edildiğini göstermektedir. 
Bu sonuçlar göstermektedir ki, Güney Afrika ekonomisinde çift yönlü nedensellik, Brezilya ve Hindistan ekonomilerinde ise finansal piyasa derinliğinden ekonomik büyümeye doğru tek yönlü bir nedensellik ilişkisi bulunmaktadır. Öte yandan Endonezya ve Türkiye ekonomilerinde finansal sistemin derinleşmesinin ekonomik büyüme üzerinde herhangi bir etkisinin olmadığı Emirmahmutoğlu ve Köse (2011) tarafından geliştirilen analiz metodunun sonuçları arasındadır. Bu durum finansal sistemin bu ülkelerde ekonomiyi yeterince finanse edemediği ve büyümeye katkı sağlayamadığı anlamına gelmektedir.

\section{Sonuç}

Finansal piyasaların gelişmesinin ekonomilerin gelişmesini sağladığına dair ampirik çalışmalara literatürde sıkça rastlanmaktadır. Bununla birlikte literatürde daha az sayıda çalışmada finansal derinlik ile ekonomik büyüme arasındaki ilişki incelenmiştir. Ancak gelişmekte olan ülkelerde finansal gelişmişlikten ziyade finansal derinliğin ekonomik büyümeye katkı açısından daha önemli olduğu son dönemde teorik olarak da tartışılmaktadır.

Gelişmekte olan ülkeler açısından derinliğin önemi, likidite ve hacmin ilgili ülkelerde yatırım için daha önemli kriterler olmasından gelmektedir. Bu bağlamda sistem içerisine giren yabancı sermayenin, derinliği artırdığı görülmektedir. Yabancı sermayenin çıkışının ise derinliği azaltacağından, ekonomik anlamda olumsuz etkisi bulunmaktadır. Bu açılamalar ışığında finansal derinliğin ekonomi üzerinde etkisinin önemli olabileceği ülkeler arasında kırılgan beşli ülkeleri saymak mantıklı olacaktır. Zira bu ülkelerde yabancı sermayeye bağımlılık dışsal şoklara duyarlılıkları da artırmaktadır ve bu nedenle 2013 yılının Mayıs ayından sonra "Kırılgan beşli" lakabını almışlardır.

Bu çalışmada kırılgan beşli ülkelerinde finansal derinlik ve ekonomik büyüme ilişkisi farklı panel veri analiz yöntemleri ile test edilmiş, 19802018 dönemine ait yıllık veriler kullanılmıştır. Analiz sonuçları, ülke grubunda iki değişken arasında çift yönlü bir ilişkinin hem kısa hem de uzun dönemde ortaya çıtığını göstermektedir. Ülke bazında yapılan analizler ise Türkiye ve Endonezya ekonomilerinde herhangi bir nedensellik 
ilişkisinin olmadığını, Hindistan ve Brezilya ekonomilerinde finansal derinlikten ekonomik büyümeye doğru bir nedenselliğin olduğunu, Güney Afrika ekonomisinde ise çift yönlü bir nedenselliğin olduğunu göstermektedir.

Bu sonuçlar, genel olarak finansal derinliğin ekonomi üzerinde etkili olduğunu gösterse de, sonuçların her ülke için geçerli olmadığı, zira kırılganlıkları ile benzer bir ekonomik yapı gösteren beş ülkeden Türkiye ve Endonezya'da finansal derinliğin ekonomi üzerinde etkili olmadığı görülmektedir. Bu sonuç iki ülkede de yatırımın ve tüketimin finansmanında finansal sistemin etkinliğinin sınırlığı olduğu yorumunun yapılmasina sebep olabilir. Öte yandan Güney Afrika, Brezilya ve Hindistan ekonomilerinde finansal derinlik ekonomik büyümeyi pozitif olarak etkilemektedir.

Tüm bu sonuçlar ışığında finansal derinliği sağlamak amacı ile gerek yurtiçi tasarrufların gerekse küresel sermaye akımlarının finansal sisteme girişi sağlanmalıdır. Bu amaçla hem ekonominin hem de finansal sistemin istikrarı sağlanarak, finansal sisteme girişi cazip hale getirecek düzenleyici ve denetleyici mekanizmaların kurulması gerekmektedir. Endonezya ve Türkiye ekonomileri özelinde muhtemel asimetrilerinden dolayı nedenselliğin bulunamaması, sonraki çalışmalarda asimetrik nedenselliği dikkate alan ekonometrik metotlar ile ülke bazında analizlerin yapılmasının mantıklı olacağını ve literatüre katkı sağlayacağını göstermektedir. 


\title{
EXTENDED ABSTRACT \\ The Effect of Financial Depth on Fragile Five Economies
}

\author{
Ferhat Şirin Sökmen \\ Şırnak University
}

The contribution of financial development level to economic growth has become one of the most discussed topics in recent years. Shortage of capital, one of the factors of production, is compensated by the financial system, especially in developing countries. For Obstfeld (1994), well-functioning financial markets have a key role to reach a high rate of economic growth.

Levine (1997) accepts that financial markets provide better opportunities for investment; factory costs to reduce; citizens to increase savings; innovation technology to be encouraged and also the number of investors who take the risk to increase. According to Svirydzenka (2016), both physical and human capital increase, and also the total factor productivity increase with the development in the financial system.

Eichengreen (1997) argues that financial integration causes financial depth; because financial integration will bring along more active, liquid and effective local financial markets at the same time. Deeper financial markets encourage more investment besides supporting economic growth.

It is to the point to empirically test whether financial deepening is really effective on the economic growth in economies with high foreign capital inflows among developing countries. The integration movement into the global financial system that started all over the world in the 1980s caused many developing countries to join in with this movement. Turkey, Brazil, India, South Africa, and Indonesia are also among those countries. Another characteristic of related economies is that their increasing fragility in financial systems after the end of the "quantitative expansion" policy of the United States Federal Reserve after the global financial crisis. Therefore, the relevant five countries are called the "Fragile Five". Foreign capital dependency of those markets lies behind the fragility. Because the 
foreign capital in developing countries moved to the United States of America after the end of the policy of quantitative expansion.

This study used panel data analysis methods to test the possible effects of the financial deepening of fragile five countries on the economic growth for the period between 1980 and 2018. It was tried to reveal which side outweighed when the positive effects of foreign capital on financial depth and also the negative effects based fragility in the mentioned countries are compared. In this regard, it is thought that this paper will contribute to literature through the perspective and countries analyzed.

Indicators regarding economic growth and the financial system of fragile five countries are reviewed in the second chapter of this paper. Thus, developments in relevant economies before the empirical analysis are diagrammatically commented; literature is summarized in the next chapter then. So, the current studies and findings can be compared. The fourth chapter gives information regarding empirical analysis; model, variables, and results of the empirical analysis are given. The last chapter gives political inferences by evaluating the results.

The relationship between financial markets and economic growth has been discussed from different perspectives in the literature. A good part of those studies analyzed the relationship between the development level of the financial system and economic growth performance while there also are the studies that analyzed the effects of criteria such as financial dominance, depth on macroeconomic variables such as economy, current account deficit, exchange rate, and investment.

This study analyzed the relationship between financial market depth index (FDI) and current per capita gross domestic product (GDPPC) in US dollars in Brazil, Indian, South African, and Turkish economies for the 1980-2018 period. The financial depth market index was obtained from the International Monetary Fund; GDP per capita was obtained from the World Bank database. The natural logarithm of GDP per capita was taken against the heteroscedasticity.

Macroeconomic structures of countries that are called fragile five similar to each other. This issue is called cross section dependence in panel data literature. The main hypothesis in cross section dependence is that there is no cross section dependence in countries within the panel while 
the alternative hypothesis is that there is cross section dependence in countries within the panel.

Literature has many empirical studies that the development of financial markets provides the development of economies. On the other hand, a fewer number of studies in the literature reviewed the relationship between financial depth and economic growth. However, it has also been theoretically discussed that the contribution of financial depth rather than financial development is more important for economic growth in developing countries.

The importance of depth in terms of developing countries is about in which countries liquidity and volume are more important for investment. In this regard, it is seen that the foreign capital within the system increases the depth. Since foreign capital outflow minimizes the depth, it has negative effects economically. So, in the light of the explanations above, it is rational to include fragile five in countries where the financial depth can have a remarkable effect on the economy. Foreign capital dependence and sensitivity to exogenous shocks have increased those countries; they have been called as "Fragile Five" since May, 2013.

This study tested the relationship between financial depth and economic growth for fragile five by panel data analysis methods via annual data of the 1980-2018 period. Analysis results show that a two-way relationship between two variables emerges in both the short and long run for the country group. Regarding the country basis, there is no causality relation in Turkish and Indonesian economies while there is causality from financial depth to economic growth in Indian Brazilian economies. Again, we can talk about a two-way causality in the South African economy.

Much as these results reveal the effectiveness of financial depth on the economy in general, the same results are not valid for each of those countries; because financial depth does not affect the economy in Turkey and India which are similar in terms of fragility. This result may bring along a comment that the effectiveness of the financial system is limited for the financing of investment and consumption in both countries. On the other hand, financial depth in South African, Brazilian, and Indian economies affects economic growth in a positive manner.

It can be said concerning all the results above that the entry of both domestic savings and global capital flows into the financial system should 
be ensured to provide financial depth. For this purpose, it is necessary to establish regulatory and supervisory mechanisms that will make entry into the financial system attractive by assuring the stability of both the economy and the financial system. There is not causality in the Indonesian and Turkish economies due to the possible asymmetries. This situation shows that it would be logical to conduct country-based analyzes with econometric methods that take into account asymmetric causality in future studies and that these analyzes will contribute to the literature.

\section{Kaynakça / References}

Abu-Bader, S. and Abu-Qarn, A. S. (2006). Financial Development and economic growth nexus: Time series evidence from Middle Eastern and North African Countries. Monaster Center for Economic Research's Discussion, 06-09.

Agheli, L. and Hadian, G. (2017). Financial development, commercial development, and economic growth in the selected emerging and the Middle Eastern Countries. International Journal of Economics and Financial Issues, 7(3), 362-370.

Apergis, N., Filippidis, I. and Economidou, C. (2007). Financial deepening and economic growth linkages: A panel data analysis. Review of World Economics, 143(1), 179-198.

Breusch, T. and Pagan, A. (1980). The Lagrange multiplier test and its application to model specification in econometrics. Rev. Econ. Stud., 47(1), 239-253.

Calderon, C. (2002). The direction of causality between financial development and economic growth. Central Bank of Chile's Working Paper No. 184.

Doğan, T. (2019). 2008 Küresel finans krizinin gelişmekte olan ülkelere etkileri: Teori ve uygulama. Yayınlanmamış Yüksek Lisans Tezi. Erciyes Üniversitesi Sosyal Bilimler Enstitüsü, Kayseri.

Eichengreen, B. (1997). Exchange rate stability and financial stability. Center for International and Development Economics Research (CIDER) Working Papers 233612, University of California-Berkeley, Department of Economics. https://doi.org/10.22004/ag.econ.233612 
Emirmahmutoğlu, F. ve Kose, N. (2011). Testing for granger causality in heterogeneous mixed panel. Economic Modelling , 28(3), 870-876. https://doi.org/10.1016/j.econmod.2010.10.018

Etibar J., Rodolfo M. and Marco P. (2019). Financial repression is knocking at the door, again. Should we be concerned?, IMF Working Paper.

Gezer, M.A. (2018). The relationship between financial deepining and economic growth: Bootstrap causality approach for the selected upper middle income countries. Theoretical and Applied Economics, 1(614), 95 -112 .

Kayhan, S., Bayat, T., Dejan, A. ve Taşar, İ. (2017). The relation between fiscal and current account deficits: The case of fragile five. Asian Journal of Economic Modelling, 5(3), 318 - 330.

Levine, R. (1997). Financial development and economic growth: Views and agenda. Journal of Economic Literature, 35(2), 688-726.

Lynch, D. (1996). Measuring financial sector development: A study of selected Asia-Pasific countries. The Developing Economies, 34(1), 3-33.

Mirdala, R. (2011). Financial deepening and economic growth in the european transition economies. Journal of Applied Economic Sciences, 6(16), 177194.

Obstfeld, M.(1994). Risk-taking, global diversification, and growth. American Economic Review, 84(5), 1310-1329.

Özşahin, Ş. ve Uysal, D. (2017). Financial deepening and economic development in MENA countries: Empirical evidence from the advanced panel method. International Journal of Economics and Finance, 9(4), 152162.

Pesaran, M.H. (2004). General diagnostic tests for cross section dependence in panels. Working Paper No:0435, University of Cambridge. https://doi.org/10.1007/s00181-020-01875-7

Pesaran, M. H. (2007). A simple panel unit root test in the presence of crosssection dependence. Journal of Applied Econometrics, 22(2), 265-312.

Pesaran, M.H., Ullah, A. and Yamagata, T. (2008). A bias-adjusted LM test of error cross section independence. Econometrics Journal, 11(1) 105-127.

Pesaran, M. H. and Yamagata, T. (2008). Testing slope homogeneity in large panels. Journal of Econometrics, 142(1), 50-93. 
Pradhan, R.P. (2010). Financial deepening, foreign direct investment and economic growth: Are they Co-integrated? International Journal of Financial Research, 1(1), 37-43.

Sahay, R. (2015). Rethinking financial deepening: Stability and growth in emerging markets. IMF Staff Discussion Note.

Shaw, E.S. (1973). Financial deepening in economic development. New York and London: Oxford University Press, Inc.

Svirydzenka, K. (2016). Introducing a new broad-based index of financial development. IMF Working Paper, WP/16/5.

Şengül, O. (2020). Financial repression and economic growth: Case of Turkey. Sosyal Bilimler Dergisi, 47(7), 265 - 273.

Smith, L. V., Leybourne, S., Kim, T. H. and Newbold, P. (2004). More powerful panel data unit root tests with an application to mean reversion in real exchange rates. Journal of Applied Econometrics, 19(2), 147-170.

Yiğitbaş, Ş. B. (2017) The Relationship between Financial Depth and Current account deficit in Turkey. International Journal of Management Economics and Business, 13(3), 507-520.

Westerlund, J. (2007). Testing for error correction in panel data. Oxford Bulletin of Economics and statistics, 69(6), 709-748.

\section{Kaynakça Bilgisi / Citation Information}

Sökmen, F. Ş. (2021). Finansal derinliğin kırılgan beşli ekonomileri üzerindeki etkisi. OPUS-Uluslararası Toplum Araştırmaları Dergisi, 18(39), 657-680. DOI: 10.26466/opus. 930561. 